\title{
ABRASION WEAR RESISTANCE OF DIFFERENT ARTIFICIAL TEETH OPPOSED TO METAL AND COMPOSITE ANTAGONISTS
}

\author{
Pâmela Carbone MELLO ${ }^{1}$, Abílio Ricciardi COPPEDÊ ${ }^{1}$, Ana Paula MACEDO², Maria da Gloria Chiarello de MATTOS$^{3}$, \\ Renata Cristina Silveira RODRIGUES ${ }^{4}$, Ricardo Faria RIBEIRO ${ }^{3}$
}

\author{
1- DDS, MSc, Graduate student, Department of Dental Materials and Prosthodontics, Dental School of Ribeirão Preto, University of São Paulo \\ Ribeirão Preto, SP, Brazil. \\ 2- Laboratory technician (Electrical engineer), Department of Dental Materials and Prosthodontics, Dental School of Ribeirão Preto, University of \\ São Paulo, Ribeirão Preto, SP, Brazil. \\ 3- DDS, MSc, PhD, Full Professor, Department of Dental Materials and Prosthodontics, Dental School of Ribeirão Preto, University of São Paulo, \\ Ribeirão Preto, SP, Brazil. \\ 4- DDS, MSc, PhD, Assistant Professor, Department of Dental Materials and Prosthodontics, Dental School of Ribeirão Preto, University of São \\ Paulo, Ribeirão Preto, SP, Brazil.
}

Corresponding address: Ricardo Faria Ribeiro - Departamento de Materiais Dentários e Prótese, Faculdade de Odontologia de Ribeirão Preto, Universidade de São Paulo. Av. do Café, s/n, 14040-904 - Ribeirão Preto, SP - Brasil. - Phone: +55-16-3602-4046 / Fax: +55-16-3633-0999 - e-mail: rribeiro@forp.usp.br

Received: July 30, 2008 - Modification: November 09, 2008 - Accepted: May 18, 2009

\begin{abstract}
$O$

ne of the most important properties of artificial teeth is the abrasion wear resistance, which is determinant in the maintenance of the rehabilitation's occlusal pattern. Objectives: This in vitro study aims to evaluate the abrasion wear resistance of 7 brands of artificial teeth opposed to two types of antagonists. Material and methods: Seven groups were prepared with 12 specimens each (BIOLUX - BL, TRILUX - TR, BLUE DENT - BD, BIOCLER - BC, POSTARIS - PO, ORTHOSIT - OR, GNATHOSTAR $\mathrm{GN}$ ), opposed to metallic ( $\mathrm{M}$ - nickel-chromium alloy), and to composite antagonists ( $\mathrm{C}$ - Solidex indirect composite). A mechanical loading device was used ( 240 cycles/min, $4 \mathrm{~Hz}$ speed, $10 \mathrm{~mm}$ antagonist course). Initial and final contours of each specimen were registered with aid of a profile projector (20x magnification). The linear difference between the two profiles was measured and the registered values were subjected to ANOVA and Tukey's test. Results: Regarding the antagonists, only OR $(\mathrm{M}=10.45 \pm 1.42 \mu \mathrm{m}$ and $\mathrm{C}=2.77 \pm 0.69 \mu \mathrm{m})$ and $\mathrm{BC}(\mathrm{M}=6.70 \pm 1.37 \mu \mathrm{m}$ and $\mathrm{C}=4.48 \pm 0.80 \mu \mathrm{m})$ presented statistically significant differences $(\mathrm{p}<$ $0.05)$. Best results were obtained with $\mathrm{PO}(\mathrm{C}=2.33 \pm 0.91 \mu \mathrm{m}$ and $\mathrm{M}=1.78 \pm 0.42 \mu \mathrm{m})$, followed by $\mathrm{BL}(\mathrm{C}=3.70 \pm 1.32 \mu \mathrm{m}$ and $\mathrm{M}=3.70 \pm 0.61 \mu \mathrm{m})$, statistically similar for both antagonists $(\mathrm{p}>0.05)$. Greater result variance was obtained with OR, which presented the worse results opposed to $\mathrm{Ni}-\mathrm{Cr}(10.45 \pm 1.42 \mu \mathrm{m})$, and results similar to the best ones against composite $(2.77 \pm 0.69$ $\mu \mathrm{m})$. Conclusions: Within the limitations of this study, it may be concluded that the antagonist material is a factor of major importance to be considered in the choice of the artificial teeth to be used in the prosthesis.
\end{abstract}

Key words: Tooth, artificial. Comparative study. Tooth abrasion.

\section{INTRODUCTION}

The abrasion wear of artificial teeth used in prosthetic rehabilitation treatments is of great clinical interest. Worn teeth alter the vertical dimension of occlusion, which may lead to craniofacial disorders, reduce chewing efficiency, cause fatigue of masticatory muscles, increase patient discomfort and impair the esthetics ${ }^{4,12,13,19}$. In order to maintain adequate function and stable occlusion, more attention should be given to the choice of the artificial teeth, which should be made considering the material of the antagonist teeth ${ }^{2,6}$.

There are three options of materials for posterior artificial teeth: porcelain, acrylic resin and metal. In removable prostheses, acrylic resin teeth are used more frequently than porcelain teeth ${ }^{5,7}$. Acrylic resin teeth present some advantages over porcelain teeth, such as: less brittleness, better connection to the denture base material, easier occlusal adjustments and repolishing, more natural appearance and less chewing noises ${ }^{15,18}$.

The low resistance to abrasion wear of the acrylic resin teeth consists in a limitation of these teeth. They do not resist parafunctional habits, and many times it is hard to maintain the vertical dimension. In order to improve abrasion wear resistance, acrylic artificial teeth with better mechanical properties have been developed, such as the interpenetrated 
polymer network (IPN) resin teeth, with polymer doublecrossed links (DCL), and resin teeth with addition of inorganic agents in their composition ${ }^{15-17}$. However, a recent study reported that these teeth, when compared to conventional ones, have worse adhesion to the denture base resin ${ }^{11}$.

The objective of this study was to evaluate the in vitro abrasion wear resistance of 7 commercial brands of artificial denture teeth (BIOLUX, TRILUX, BLUE DENT, BIOCLER, POSTARIS, ORTHOSIT, GNATHOSTAR), opposed to metallic antagonists $(\mathrm{M}$ - nickel-chromium alloy) and composite antagonists $(\mathrm{C}$ - Solidex indirect composite). Although some of these artificial teeth are commercially available only in the Brazilian market, all of them have formulations found worldwide and can therefore indicate the expected results when used in dental prostheses.

\section{MATERIAL AND METHODS}

Figure 1 shows the artificial denture teeth evaluated in this study. Seven groups of 12 specimens each were prepared and divided in two subgroups: one group was tested opposed to metallic antagonists (M - Ni-Cr alloy [Vera Bond II, Aalba Dent. Inc., Cordelia, CA, USA]), and another group was tested opposed to composite antagonists (C - indirect composite, (Solidex [Shofu Inc., Tokyo, Japan]). Six maxillary first premolars of each brand were used $(\mathrm{N}=84)$. The Ni-Cr alloy was selected because it is extensively used in oclusal surfaces of fixed partial dentures, as clinically observed in partially edentulous patients.

The 84 specimens were included in 1-inch PVC rings with self-curing acrylic resin, using a custom-made parallelometer (Ribeirão Preto Dental School, University of São Paulo), with a griping tip that stabilized the specimen

\begin{tabular}{|c|c|c|c|c|}
\hline Groups & $\mathbf{N}$ & Composition* & Commercial Brand & Manufacturer \\
\hline $\mathrm{BD}$ & 12 & $\begin{array}{c}\text { High-density } \\
\text { polymethylmethacrylate, cross- } \\
\text { linked }\end{array}$ & BLUE DENT & $\begin{array}{c}\text { Blue Dent Dental, Pirassununga, } \\
\text { Brazil }\end{array}$ \\
\hline $\mathrm{BL}$ & 12 & $\begin{array}{l}\text { Polymethylmethacrylate; } \\
\text { Polymerized Ethyleneglycol } \\
\text { Dimethacrylate (EDMA); } \\
\text { Fluorescent; Biocompatible } \\
\text { Pigments }\end{array}$ & BIOLUX & $\begin{array}{l}\text { VIPI Indústria, Comércio, } \\
\text { Exportação e Importação de } \\
\text { Produtos Odontológicos Ltda, } \\
\text { Pirassununga, Brazil }\end{array}$ \\
\hline $\mathrm{BC}$ & 12 & $\begin{array}{l}\text { Polymethylmethacrylate, cross- } \\
\text { linked; Fluorescent }\end{array}$ & BIOCLER GII & $\begin{array}{l}\text { DentBras Indústria, Comércio, } \\
\text { Importação e Exportação de } \\
\text { Produtos Odontológicos Ltda, } \\
\text { Pirassununga, Brazil }\end{array}$ \\
\hline TR & 12 & $\begin{array}{l}\text { Polymethylmethacrylate; } \\
\text { Polymerized Ethyleneglycol } \\
\text { Dimethacrylate (EDMA); } \\
\text { Fluorescent; Biocompatible } \\
\text { Pigments }\end{array}$ & TRILUX & $\begin{array}{l}\text { VIPI Indústria, Comércio, } \\
\text { Exportação e Importação de } \\
\text { Produtos Odontológicos Ltda, } \\
\text { Pirassununga, Brazil }\end{array}$ \\
\hline $\mathrm{PO}$ & 12 & $\begin{array}{l}\text { Synthetic polymer based on } \\
\text { Polymethylmethacrylate; } \\
\text { double cross linked }\end{array}$ & SR POSTARIS DCL & $\begin{array}{c}\text { Ivoclar Vivadent AG.Schaan, } \\
\text { Liechtenstein }\end{array}$ \\
\hline GN & 12 & $\begin{array}{l}\text { Synthetic polymer based on } \\
\text { Polymethylmethacrylate }\end{array}$ & GNATHOSTAR & $\begin{array}{c}\text { Ivoclar Vivadent AG.Schaan, } \\
\text { Liechtenstein }\end{array}$ \\
\hline OR & 12 & $\begin{array}{l}\text { Microfilled resin composite } \\
\text { (Isosit+Inorganic fillers) } \\
\text { (urethane dimethacrylate - } \\
\text { UDMA) }\end{array}$ & SR ORTHOSIT PE & $\begin{array}{c}\text { Ivoclar Vivadent AG.Schaan, } \\
\text { Liechtenstein }\end{array}$ \\
\hline
\end{tabular}

FIGURE 1- Groups of artificial teeth

*Based on manufacturers' informations 
during the inclusion.

For preparation of the antagonist tablets, a $20-\mathrm{mm}-$ diameter polytetrafluoroethylene matrix was manufactured in the Department of Dental Materials and Prosthodontics of Ribeirão Preto Dental School, University of São Paulo (DDMP), with 2- and 3-mm-thick spacers. Using 2-mmthick spacers and Picodip wax (Renfert GmbH, Hilzingen, Germany) liquefied in a wax dipping pot (Hotty Led, Renfert, Hilzingen, Germany), patterns were obtained, and were included with phosphate-based investment (Termocast, Polidental Ind. Bras. Ltda, São Paulo, Brazil), and cast with $\mathrm{Ni}-\mathrm{Cr}$ alloy in the Discovery Plasma casting machine (EDG Equipments and Controls Ltda, São Carlos, SP, Brazil), under vacuum and inert argon atmosphere. The castings obtained were sandblasted with $100-\mu \mathrm{m}$ aluminum oxide stream, under $80 \mathrm{psi}\left(5.62 \mathrm{kgf} / \mathrm{cm}^{2}\right)$ pressure. Using the same matrix, but with the 3-mm-thick spacer, 12 other tablets were obtained with the Solidex composite. Each tablet was obtained using an incremental technique, according to which 2 composite increments were built, each one subjected to a 90-s curing cycle in a light-curing unit (UniXS, Heraeus Kulzer GmbH, Hanau, Germany). The polymerized specimen was retrieved from the matrix and subjected to more 90 -s of light curing.

According to the DIN method stated by the ISO/TS 14569-2 standard, the surface of the antagonist tablet must have a surface roughness of $0.75 \mu \mathrm{m}$. Thus, all antagonist tablets were prepared with 300-, 600- and 1200-grit silicon carbide paper in a decreasing sequence of abrasiveness, and their surface roughness was read in a surface roughness meter (SPJ-2, Mitutoyo, Tokyo, Japan).

Before abrasion wear tests, the specimens were taken to a profile projector (Nikon $6 \mathrm{C}$, Tokyo, Japan) with a $20 \mathrm{x}$ magnification and were individually placed in a positioning platform that allows further placement of the specimen in the same position for the post-test measurements. A vegetable graph paper was used to obtain each specimen's profile. The original profile of the specimens was traced for posterior analysis of contour changes.

The abrasion wear tests were performed in the mechanical loading device developed at the DDMP. In this device, an electrical motor moves a lever arm with a 265 cycles/min speed. An acrylic recipient is attached to the device's lever arm, and performs a 10-mm course, resulting in a linear speed of $88 \mathrm{~mm} / \mathrm{s}$. The test assembly was installed inside the acrylic recipient.

Specimens were placed in a pole with vertical adjustment, allowing it to be positioned over the antagonist. Once the pole was completely released, a load of $5 \mathrm{~N}$, corresponding to the whole weight of the assembly, was applied to the specimens. This mechanical loading device was designed according to the ISO/TS 14569-2 standard (Dental Materials - Guidance on testing of wear - Part 2: Wear by two - and/or three-body contact, 2001) under the Freiburg Method. The tests completed 40,000 cycles, simulating approximately 120 days of normal oral function ${ }^{4}$ (150 $\mathrm{min}, 4 \mathrm{~Hz}$ ), with specimens and antagonists completely immerse in deionized water (Figure 2).

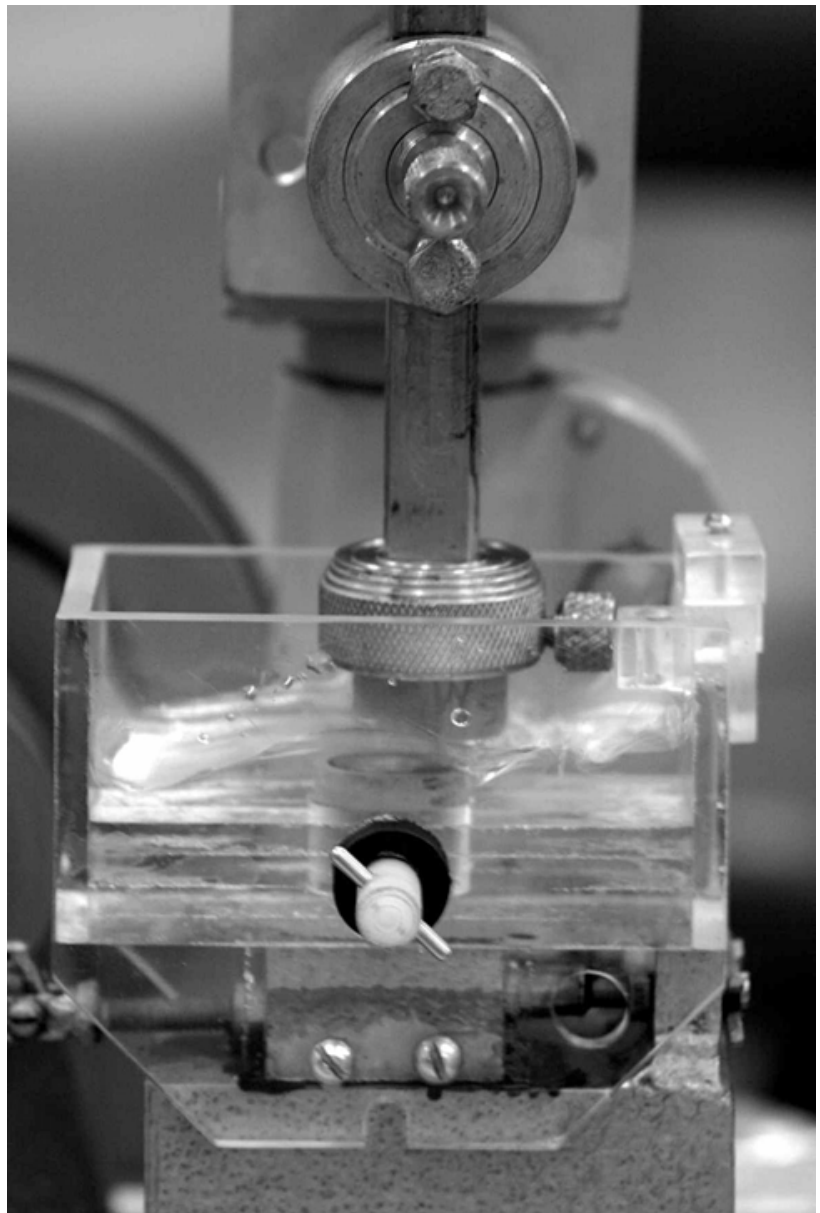

FIGURE 2- Wear abrasion test device

Specimens and composite antagonists were stored in distilled water at $37^{\circ} \pm 1^{\circ} \mathrm{C}$ during 7 days before the tests. In the test machine, the antagonist tablet was placed into a recipient with deionized water. Immediately after removal of the water storage, the specimens were dried with absorbent paper and a gentle air stream, and had their final contour traced in the profile projector (Nikon 6C, Tokyo, Japan), over the initial profile traced. The measure of the abrasion wear was determined by the linear difference between the two profiles, utilizing a digital paquimeter (Mitutoyo CD 15C, Japan, Tokyo) accurate to the nearest $0.01 \mathrm{~mm}$ (Figure $3)$.

The wear values $(\mu \mathrm{m})$ of all tested specimens, grouped by antagonist, were subjected to one-way ANOVA and Tukey's test. The paired t-test was used for comparisons within each specimen group, among different antagonists, All statistics were performed using the SPSS statistical package (SPSS Inc., Chicago, IL, USA).

\section{RESULTS}

The results obtained in the abrasion wear resistance tests by the artificial teeth are shown in Figure 4.

There were statistically significant differences $(p=0.001)$ for comparisons among the different artificial teeth against 




FIGURE 3- Measure of abrasion wear determined by the linear difference between the initial and final profiles

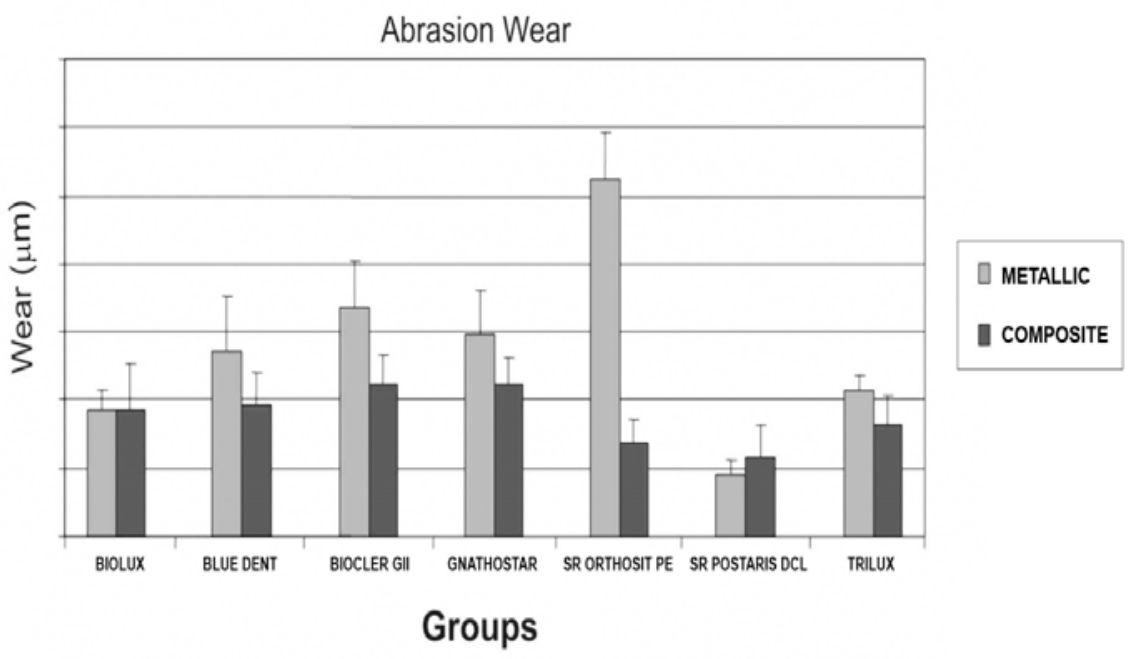

FIGURE 4- Original values, mean values and standard deviations of all specimens opposed to the antagonists (metallic, NiCr, and composite, Solidex) after the abrasion wear resistance tests (in $\mu \mathrm{m}$ ) - please refer to text in order to follow statistically significant differences

composite antagonist. PO $(2.33 \pm 0.91 \mu \mathrm{m})$ and $\mathrm{OR}(2.77 \pm$ $0.69 \mu \mathrm{m})$, which had the lowest wear mean values, were significantly different from groups BC $(4.48 \pm 0.80 \mu \mathrm{m})$ and $\mathrm{GN}(4.50 \pm 0.73 \mu \mathrm{m})$, which had the highest wear mean values.

Statistically significant differences $(p=0.000)$ were found when the groups were compared against metallic antagonist. OR $(10.45 \pm 1.42 \mu \mathrm{m})$ presented the highest wear mean value, and differed significantly from all other groups $(p<0.001)$. There were significant differences $(p<0.05)$ between BC $(6.70 \pm 1.37 \mu \mathrm{m})$ and TRI $(4.30 \pm 0.43 \mu \mathrm{m})$, $\mathrm{BL}(3.70 \pm 0.61 \mu \mathrm{m})$ and $\mathrm{PO}(1.78 \pm 0.42 \mu \mathrm{m})$. Significant differences $(\mathrm{p}<0.05)$ were also found when $\mathrm{BD}(5.37 \pm 1.65$ $\mu \mathrm{m})$ and TRI $(4.30 \pm 0.43 \mu \mathrm{m})$ were compared to PO (1.78 $\pm 0.42 \mu \mathrm{m}$ ), which had the lowest wear mean values (Figure 3).

In order to compare the wear for each group caused by the two types of antagonists, a paired-sample t-test were performed. Significant differences were observed for BC $(\mathrm{p}=0.007)$, which presented mean wear of $4.48 \pm 0.80 \mu \mathrm{m}$ against composite and $6.70 \pm 1.37 \mu \mathrm{m}$ against metal, and for OR $(\mathrm{p}=0.000)$, which presented mean wear of $2.77 \pm$ $0.69 \mu \mathrm{m}$ against composite and $10.45 \pm 1.42 \mu \mathrm{m}$ against metal. All other groups had no statistically significant differences from each other $(\mathrm{p}>0.05)$.

No wear was observed in the antagonists.

\section{DISCUSSION}

This study excluded clinical variables, such as neuromuscular forces and movements, saliva $\mathrm{pH}$ and lubrication, oral hygiene habits and diet, because according to previous studies, those factors are very difficult to control, 
and are costly and time consuming ${ }^{10,15}$.

Prosthetic rehabilitation success depends on adopting correct procedures in order to obtain comfort, function and esthetics. The choice of the materials that will replace missing dental structures is a critical clinical issue for both the professional and the patient. The dentist has to have knowledge and discernment to adjust the patient's expectations to the characteristics of the materials indicated for the case. Also, the dentist must be familiar with the properties of the various artificial teeth available in the market and must be aware of patient's characteristics, such as diet and presence of parafunctional habits, in order to obtain the best possible treatment prognosis ${ }^{1,7}$.

Stober, et al. ${ }^{15}$ (2006) has stated that natural enamel is an unsuitable antagonist material for standardized wear tests because the composition, shape and wear properties of biological substances are highly variable. Based on this information, human enamel was not used in this study. However, it should be considered that the interaction with the enamel provide important data for the evaluation of artificial teeth.

In the two-body wear test used in the present study, there is direct contact between the tested material and its respective antagonist, with no intermediate material, but running water. Other studies, however, used an intermediate material to simulate the food bolus. Kadokawa, et al. ${ }^{9}$ (2006) evaluated the abrasion wear and other abrasive properties of porcelain, gold alloy, composite resin and human enamel using 2-body and 3-body conditions (PMMA slurry). The authors concluded that the wear values in 3-body wear were significantly smaller.

According to Whitman, et al. ${ }^{17}$ (1987) and Hirano, et al. $^{7}$ (1998), artificial teeth made of improved acrylic resin (IPN, DCL), or polymers with addition of inorganic agents are more resistant than conventional polymethylmetacrylate (PMMA) teeth. In a recent abrasion wear resistance test, cross-linked teeth or teeth with addition of an inorganic layer presented greater abrasion wear resistance than conventional PMMA teeth ${ }^{16}$. Other clinical studies, however, did not find significant differences among the wear presented by conventional PMMA teeth and improved acrylic teeth (DCL, IPN $)^{5,8,10,12}$

Based on the findings of Ghazal, et al..$^{5}$ (2008), the test performed in this study correspond to an approach of twobody wear with direct contact between the artificial teeth tested and the antagonist, which produces a mixed wear of adhesion, attrition and fatigue. Some authors have stated that this condition is especially important when considering complete dentures with a bilaterally balanced occlusion ${ }^{6,15}$. Additionally, in a 2-body wear test only direct interactions between surfaces of sample and antagonist cause a substance $\operatorname{loss}^{15}$.

In the present study, the group PO (double cross-linking [DCL] polymethylmetacrylate) presented the smallest wear mean values, for both metallic and composite antagonists. The group OR (polymer with inorganic filling) presented the highest wear mean values against metallic antagonists among all other groups tested. However, it presented small wear mean values against composite antagonists, similar to the best results obtained by the other groups, which suggests a different type of interaction, possibly justified by the fact that both types of artificial teeth are based on the same polymer type. Brigagão, et al. ${ }^{2}$ (2005) obtained smaller values of weight and height loss for PO teeth. However, these authors did not obtain enough wear on the tested specimens, and no significant differences were observed among the groups, using 200,000 cycles, which corresponded to 1 year of clinical function ${ }^{14}$, with $400 \mathrm{~g}$ load.

Possibly due to the load used in this study, which was low $(5 \mathrm{~N})$, no wear was measured in the antagonists. Because the rough surface characteristics ( $75 \mu \mathrm{m}$, accordingly to the DIN method of the ISO/TS 14569-2 standard) just a mark was visible. The vertical substance loss measured in this study, as a consequence of the sliding contact of a buccal cusp of artificial teeth and the antagonist tablets, represents the abraded area of the teeth. Each artificial teeth used in this study has a particular cusp shape, and the contact area increased as the abrasion test was performed. In order to avoid higher influence of this increased contact area, the tests performed were limited to simulate a 120-day use of the teeth. In addition, the cusp shape in this study was in accordance with the sample dimensions described in the ISO/ TS 14569-2 standard (Dental Materials - Guidance on testing of wear - Part 2: Wear by two - and/or three-body contact, 2001) under the Freiburg Method. However, this is a limitation of the method used ${ }^{3}$. Other evaluations, with higher loads, must be performed to determine the effects on both the artificial teeth and antagonist materials. Reis, et al. ${ }^{13}$ (2008) used a canine tooth to test the in vitro wear resistance for three types of PMMA artificial teeth in a similar way, and observed that tested PMMA denture teeth have significantly different wear resistance against abraded ceramic. The highest values were found for high-strength PMMA teeth than conventional PMMA teeth.

The findings of present in vitro study are important for the comparison of the abrasion wear resistance of different commercially available artificial teeth against different types of antagonists. However, clinical trials with these materials for longer periods are still necessary. In addition, new studies should be accomplished to establish the wear resistance of artificial teeth when they are used opposing materials with the same wear characteristics.

\section{CONCLUSIONS}

Based on the methodology applied to this study, considering the inherent limitations and the obtained results, it may be concluded that the antagonist material present on (or planed for) a clinical rehabilitation is a factor of major importance to be considered for the choice of the artificial teeth to be used in the prosthesis. OR was the group that presented the greatest result variance regarding the abrasion wear resistance; it also presented the worst result opposed to metallic antagonist $(10.45 \pm 1.42 \mu \mathrm{m})$, and a result similar 
to the best ones opposed to composite antagonists $(2.77 \pm$ $0.69 \mu \mathrm{m})$. The group PO presented the smallest wear mean values, both for metallic $(1.70 \pm 0.42 \mu \mathrm{m})$ and composite $(2.30 \pm 0.91 \mu \mathrm{m})$ antagonists. In the light of the obtained results, dentist's decision to indicate any of the artificial teeth tested in this study can be made based on the analysis of important characteristics in determining its functionality and esthetics, allied to the cost of the material.

\section{ACKNOWLEDGMENTS}

The authors thank to Mr. Luiz Sérgio Soares and Mr. Paulo Donato Frighetto for their technical assistance, as well as the manufacturers for donation of artificial teeth.

\section{REFERENCES}

1- Assunção WG, Barbosa DB, Goiato MC. Evaluation of the wear rates of eight different brands of artificial resin teeth. Cienc Odontol Bras. 2005;8:6-12.

2- Brigagão V, Camargo F, Neisser M. In vitro wear evaluation of denture teeth. Cienc Odontol Bras. 2005;8:55-63.

3- DeLong R. Intra-oral restorative materials wear: rethinking the current approaches - how to measure wear. Dent Mater. 2006;22:702-11.

4- Gateau P, Sabek M, Dailey B. Fatigue testing and microscopic evaluation of post and core restorations under artificial crowns. J Prosthet Dent. 1999;82:341-7.

5- Ghazal M, Yang B, Ludwig K, Kern M. Two-body wear of resin and ceramic denture teeth in comparison to human enamel. Dent Mater. 2008;24:502-7.

6- Hahnel S, Behr M, Handel G, Rosentritt M. Two-body wear of artificial acrylic and composite resin teeth in relation to antagonist material. J Prosthet Dent. 2009;101:269-78.

7- Hirano S, May KB, Wagner WC, Hacker $\mathrm{CH}$. In vitro wear of resin denture teeth. J Prosthet Dent. 1998;79:152-5.

8- Jooste C, Geerts G, Adams L. Comparison of the clinical abrasion resistance of six commercially available denture teeth. J Prosthet Dent. 1997;77:23-7.

9- Kadokawa A, Suzuki S, Tanaka T. Wear evaluation of porcelain opposing gold, composite resin, an enamel. J Prosthet Dent. 2006;96:258-65.

10- Lindquist TJ, Ogle RE, Davis EL. Twelve-month results of a clinica wear study of three artificial tooth materials. J Prosthet Dent. 1995;74:15661

11- Loyaga-Rendon PG, Takahashi H, Hayakawa I, Iwasaki N. Compositional characteristics and hardness of acrylic and composite resin artificial teeth. J Prosthet Dent. 2007;98:141-9.

12- Ogle RE, Davis EL. Clinical wear study of three commercially available artificial tooth materials: thirty-six month results. J Prosthet Dent. 1998;79:145-51

13- Reis KR, Bonfante G, Pegoraro LF, Conti PCR, Oliveira PCG, Kaizer $\mathrm{OB}$. In vitro wear resistance of three types of polymethylmethacrylkate denture teeth. J Appl Oral Sci. 2008;16:176-80.
14- Sato Y, Akagawa Y, Okhawa S. An in vitro study of high-strength resin posterior tooth wear. Int J Prosthodont. 1997;10:28-34.

15- Stober T, Lutz T, Gilde H, Rammelsberg P. Wear of resin denture teeth by two-body contact. Dent Mater. 2006;22:243-9.

16- Suzuki S, Tamura F. In vitro wear of nano-composite denture teeth. J Prosthodont. 2004;13:238-43

17- Whitman DJ, McKinney JE, Hinman RW, Hesby RA, Pelleu GB Jr. In vitro wear rates of three types of commercial denture tooth materials. $\mathrm{J}$ Prosthet Dent. 1987;57:243-6.

18- Winkler S, Monasky GE, Kwok J. Laboratory wear investigation of resin posterior denture teeth. J Prosthet Dent. 1992;67:812-4.

19- Zeng J, Sato Y, Ohkubo C, Hosoi T. In vitro wear resistance of three types of composite resin denture teeth. J Prosthet Dent. 2005;94:453-7. 